\title{
Anti-Plasmodial Polyvalent Interactions in Artemisia annua L. Aqueous Extract - Possible Synergistic and Resistance Mechanisms
}

\author{
John O. Suberu ${ }^{1}$, Alexander P. Gorka², Lauren Jacobs², Paul D. Roepe ${ }^{2}$, Neil Sullivan ${ }^{3}$, Guy C. Barker ${ }^{1 *}$, \\ Alexei A. Lapkin ${ }^{4 \odot}$ \\ 1 School of Life Sciences, University of Warwick, Coventry, United Kingdom, 2 Centre for Infectious Disease, Department of Chemistry, Georgetown University, \\ Washington, District of Columbia, United States of America, 3 Sensapharm Ltd, Business and Innovation Centre, Sunderland, United Kingdom, 4 Department of \\ Chemical Engineering and Biotechnology, University of Cambridge, Cambridge, United Kingdom
}

\begin{abstract}
Artemisia annua hot water infusion (tea) has been used in in vitro experiments against $P$. falciparum malaria parasites to test potency relative to equivalent pure artemisinin. High performance liquid chromatography (HPLC) and mass spectrometric analyses were employed to determine the metabolite profile of tea including the concentrations of artemisinin $\left(47.5 \pm 0.8 \mathrm{mg} \mathrm{L}^{-1}\right)$, dihydroartemisinic acid $\left(70.0 \pm 0.3 \mathrm{mg} \mathrm{L}^{-1}\right)$, arteannuin $B\left(1.3 \pm 0.0 \mathrm{mg} \mathrm{L}^{-1}\right)$, isovitexin $\left(105.0 \pm 7.2 \mathrm{mg} \mathrm{L}^{-1}\right)$ and a range of polyphenolic acids. The tea extract, purified compounds from the extract, and the combination of artemisinin with the purified compounds were tested against chloroquine sensitive and chloroquine resistant strains of $P$. falciparum using the DNA-intercalative SYBR Green I assay. The results of these in vitro tests and of isobologram analyses of combination effects showed mild to strong antagonistic interactions between artemisinin and the compounds (9-epi-artemisinin and artemisitene) extracted from $A$. annua with significant (IC ${ }_{50}<1$ $\mu \mathrm{M})$ anti-plasmodial activities for the combination range evaluated. Mono-caffeoylquinic acids, tri-caffeoylquinic acid, artemisinic acid and arteannuin B showed additive interaction while rosmarinic acid showed synergistic interaction with artemisinin in the chloroquine sensitive strain at a combination ratio of $1: 3$ (artemisinin to purified compound). In the chloroquine resistant parasite, using the same ratio, these compounds strongly antagonised artemisinin antiplasmodial activity with the exception of arteannuin B, which was synergistic. This result would suggest a mechanism targeting parasite resistance defenses for arteannuin B's potentiation of artemisinin.
\end{abstract}

Citation: Suberu JO, Gorka AP, Jacobs L, Roepe PD, Sullivan N, et al. (2013) Anti-Plasmodial Polyvalent Interactions in Artemisia annua L. Aqueous Extract - Possible Synergistic and Resistance Mechanisms. PLoS ONE 8(11): e80790. doi:10.1371/journal.pone.0080790

Editor: Gabriele Pradel, RWTH Aachen University, Germany

Received June 28, 2013; Accepted October 7, 2013; Published November 14, 2013

Copyright: $\odot 2013$ Suberu et al. This is an open-access article distributed under the terms of the Creative Commons Attribution License, which permits unrestricted use, distribution, and reproduction in any medium, provided the original author and source are credited.

Funding: This study was funded by Engineering and Physical Sciences Research Council (EPSRC, UK) and SensaPharm Ltd via an Industrial CASE PhD studentship. The award was allocated competitively by Chemistry Innovation Knowledge Transfer Network (CIKTN, UK). The funders had no role in study design, data collection and analysis, decision to publish, or preparation of the manuscript.

Competing interests: The affiliation of Dr Sullivan with Sensapharm is eclared however this affiliation does not alter our adherence to all the PLOS ONE policies on sharing data and materials, as detailed online in your guide for authors. This does not alter our adherence to all the PLOS ONE policies on sharing data and materials.

*E-mail: guy.barker@warwick.ac.uk

๑. These authors contributed equally to this work.

\section{Introduction}

The use of Artemisia annua (Qing Hao) in traditional Chinese pharmacopeia includes the treatment of fevers and chills [1,2]. In the 1970s, the active principle in the extract was isolated and identified as artemisinin (1), a sesquiterpene lactone. The effectiveness of artemisinin is structurally due to the trioxane pharmacophore and the activation of the compound occurs via the cleavage of the endoperoxide bridge [3]. The mechanism for the activation of artemisinins and their interaction with the parasite are not fully understood. Different but not mutually exclusive mechanistic models have been proposed with evidence for and against each model [4]. A number of studies $[5,6]$ have suggested that artemisinins act by heme dependent activation of the trioxane bridge in the parasites' food vacuole to produce free radicals which then disrupt heme detoxification and therefore lead to parasite toxicity. This hypothesis and other alternative mechanisms for the mode of action of artemisinins have been studied and reviewed by several authors [3,4,7-13]. Artemisinin and its derivatives have now been established in various combination therapies (ACTs) as effective anti-malarial treatments against multidrug-resistant $P$. falciparum infection [14,15]. 
In some parts of Asia and Africa, a hot water infusion (tea) of the plant is used as a self-medication for malaria. The use of tea in this way has raised concern of the possible development of parasite resistance as a result of un-standardised use of artemisinin in these tea preparations [16]. Consequently, the World Heath Organisation (WHO) in a position statement has called for "extensive fundamental and clinical research" which demonstrates both efficacy and safety for the use of tea and other non-pharmaceutical forms of $A$. annua extract before recommendation for treating malaria [17].

The recipes in ancient Chinese texts for preparing Qing Hao extracts for the treatment of fevers include soaking, followed by wringing or pounding, followed by squeezing the fresh herb $[1,2,18]$. In their study, Rath et al. [19] found that adding boiling water to the leaves, stirring briefly and leaving covered for 10 minutes, then filtering and gently squeezing the leaves to release residual water gave the best extraction efficiency $(86 \%)$ for artemisinin in the preparation, relative to the total amount of the compound in leaves. In the literature, a range of aqueous extraction efficiencies $(25-90 \%)$ has been reported for artemisinin [19-21]. Due to the differences in the content of artemisinin in tea preparation, Van der Kooy and Verpoorte [21] quantified artemisinin in tea prepared by different methods. They observed that the extraction efficiency is temperaturesensitive and that efficiencies of above $90 \%$ are attainable.

In some studies evaluating the activity of $A$. annua extracts, the amount of artemisinin in these extracts cannot fully account for its effectiveness against Plasmodium parasites in vitro and in vivo $[16,19]$. Mouton et al. however did not find any evidence of improved potency for their extracts relative to the artemisinin content [22]. Apart from artemisinin, there are around 30 other sesquiterpenes and over 36 flavonoids identified in the plant (Figure 1), some of which have shown limited anti-plasmodial properties [23]. Five flavonoids, including casticin (7), have been shown to potentiate the activity of artemisinin [24,25]. Interestingly, the potentiating effect of these flavonoids was not observed with chloroquine (CQ). Billia et al. [26] observed that although these flavonoids have no effect on hemin (chloroferriprotoporphyrin IX) themselves, they do catalyse a reaction between artemisinin and hemin.

Weathers and Towler [27] have shown that polymethoxylated flavonoids like casticin are poorly extracted and unstable in the aqueous tea infusion. This suggests that compounds other than this class of flavonoids are likely to be responsible for the reported improvement in the potency of artemisinin in tea infusion. A recent analysis by Cabonara et al. [28] of tea prepared from $A$. annua leaves by infusion in hot water for 1, 24 and 48 hours, identified a series of caffeoyl and feruloyl-quinic acids as main components of the infusion, together with some flavonoids. Chlorogenic or caffeoylquinic acids (CQAs) are esters of caffeic and quinic acids (Figure 1). They possess a broad spectrum of pharmacological properties, including antioxidant, hepato-protectant, antibacterial, antihistaminic, chemo-preventive and other biological effects [29-32].

To our knowledge, only the interactions of artemisinin with the poorly extracted poly-methoxylated flavonoids found in Artemisia tea have been studied. This study therefore aims at understanding other possible interactions and mechanisms involved in artemisinin activity in the plant extract, and the effects of these interactions on parasite resistance to artemisinin.

\section{Materials and Methods}

\section{1: Chemicals}

Reference standards of artemisinin (98\%), rosmarinic acid, caffeic acid and casticin were obtained from Sigma-Aldrich (Dorset, UK). Dihydroartemisinic acid (> 96\%) was purchased from Apin Chemicals (Oxfordshire, UK). 9-Epi-artemisinin (98\%) was sourced from Sensapharm Ltd (Sunderland, UK). Artemisitene, artemisinic acid and arteannuin B were kindly provided by Walter Reed Army Institute of Research (Washington, DC, USA). The chlorogenic acids (>99\%) and isovitexin (>99\%) were obtained from Biopurify (China). LC-MS grade formic acid in water, acetonitrile and HPLC grade acetonitrile were obtained from Fisher Scientific (UK). Purified

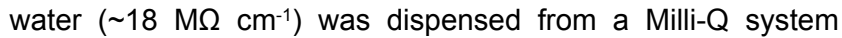
(Millipore, UK).

\section{2: Plant materials}

High yielding, dried $A$. annua biomass was obtained from BIONEXX Madagascar and stored under dark, cool conditions until use.

\section{3: Plant extracts}

A. annua tea was prepared according to published methods with slight modification [1,33]. Briefly, $1 \mathrm{~L}$ of boiling water was added to $5 \mathrm{~g}$ of dried plant material, stirred and stored in the dark for 1 hour. The extract was filtered in vacuo and lyophilised after freezing to obtain the dried tea extract which was used in the Plasmodium assays and in metabolite profiling.

\section{4: Sample preparation - solubility studies}

The solubility of artemisinin, artemisitene and 9-epiartemisinin in aqueous solvent at room temperature $\left(22^{\circ} \mathrm{C}\right)$ was determined by the method employed by Wang et al. [34], with modifications. A saturated solution was prepared by dissolving excess amount of the pure (> 99.0\%) standard of each material in $1 \mathrm{~mL}$ de-ionised water (MS grade, Brucker, UK) and vortexed. This suspension was allowed to settle and the supernatant filtered through a $0.1 \mu \mathrm{m}$ syringe filter (Fisher Scientific, UK). Appropriate volume of the filtrate was diluted with the mobile phase for mass spectrometry (MS/MS) analysis.

\section{5: Mass spectrometry method for artemisinins}

The method by Suberu et al. [35] was employed. Briefly, the MS/MS system was operated with an ESI interface in positive ionisation mode (ESI+). The cone and desolvation gas flow rates were set at $45 \mathrm{~L} \mathrm{~h}^{-1}$ and $800 \mathrm{~L} \mathrm{~h}^{-1}$, respectively. The MS parameters were automatically defined using Waters IntelliStart@ software for the tuning and calibration of the tandem quardrupole analyser (TQD) and subsequently manually optimized for all analytes. Capillary voltage was set at 


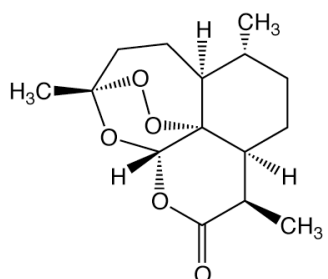

(1) artemisinin<smiles>CC1=CC2C(CC1)[C@@H](C)CC[C@@H]2C(C)C(=O)O</smiles>

(4) dihydroartemisinic acid<smiles>COc1ccc(-c2oc3cc(C)c(C)c(O)c3c(=O)c2OC)cc1O</smiles>

(7) casticin<smiles>O=C(O)c1ccc(O)c(O)c1</smiles>

Caffeoyl group (CA)

(10) caffeic acid<smiles>[R6]OC1CC(O)(C(=O)O)CC([R6])C1O[R6]</smiles>

(11-17) quinic acid

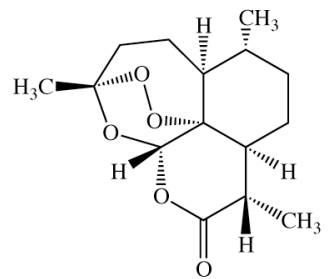

(2) 9-epi-artemisinin<smiles>C=C1C(=O)O[C@]23[C@H]1CC[C@H](C)[C@H]2CC[C@]1(C)O[C@]13C</smiles>

(5) arteannuin B<smiles>O=C1CC(c2ccc(O)cc2)Oc2cc(O)c([C@H]3O[C@H](CO)[C@@H](O)[C@H](O)[C@H]3O)c(O)c21</smiles>

(8) isovitexin

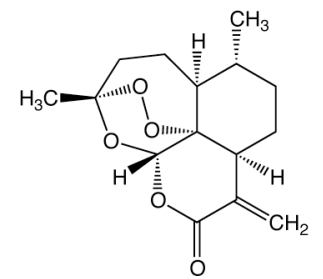

(3) artemisitene

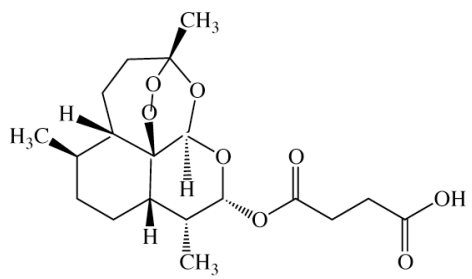

(6) artesunate<smiles>O=C(/C=C/c1ccc(O)c(O)c1)OC(Cc1ccc(O)c(O)c1)C(=O)O</smiles>

(9) rosmarinic acid

(11) 3-caffeoylquinic acid $\quad$ CA $\quad H \quad H$

(12) 4-caffeoylquinic acid

(13) 5-caffeoylquinic acid

(14) 3,4-di-caffeoylquinic acid

(15) 3,5-di-caffeoylquinic acid

(16) 4,5-di-caffeoylquinic acid

(17) 3,4,5-tri-caffeoylquinic acid
$\mathrm{H} \quad \mathrm{CA}$

$\mathrm{H}$

$\mathrm{H} \quad \mathrm{H} \quad \mathrm{CA}$

CA $\mathrm{CA} \quad \mathrm{H}$

CA $\mathrm{H} \quad \mathrm{CA}$

$\mathrm{H} \quad \mathrm{CA} \quad \mathrm{CA}$

CA CA CA

Figure 1. Structures of some artemisinin related compounds, flavonoids and acids identified in $A$. annua extract. doi: 10.1371/journal.pone.0080790.g001

2.8 Kilovolts, collision voltage at 7 volts, source temperature was $150{ }^{\circ} \mathrm{C}$ and cone voltage was set at 24 volts. A multiple reaction-monitoring

$283 \rightarrow 219+229+247+265$,
(MRM) transition of $283 \rightarrow 209+219+247+265$, 
$281 \rightarrow 217+227+245+263$ for artemisinin, 9-epi-artemisinin and artemisitene was employed. Quantification was determined using MRM modes for the above transitions. The dwell time was automatically set at 0.161 seconds. Data were acquired by MassLynx v4.1 software and processed for quantification with QuanLynx v4.1 (Waters Corp., Milford, MA, USA).

The high performance liquid chromatography (HPLC) system coupled to the mass spectrometer consisted of a binary pump, a cooling auto-sampler with an injection loop of $10 \mu \mathrm{L}$ set at 10 ${ }^{\circ} \mathrm{C}$. The column heater was set at $30^{\circ} \mathrm{C}$ and a Genesis $₫$ Lightn C18 column $(100 \times 2.1 \mathrm{~mm} ; 4 \mu \mathrm{m})($ Grace, IL, USA) protected by an Acquity-LC column in-line filter unit $(0.2 \square \mu \mathrm{m}$ in-line frit) was used for separation of metabolites. The mobile phase consisted of $A$ : $0.1 \%$ formic acid in water and B: $0.1 \%$ formic acid in acetonitrile used in the following gradient: $0-7.00 \mathrm{~min}$, 25-98\% B; 7-9.5 min, 98\% B; 9.5-10 min, 98-25\% B; 10-15 min, $25 \% \mathrm{~B}$; at a flow rate of $0.4 \mathrm{~mL} \mathrm{~min}^{-1}$. Weak wash solvent was $10 \%$ acetonitrile, strong and needle wash solvent was a mixture of acetonitrile, propan-2-ol, methanol and water $(30: 30: 30: 10 \mathrm{v} / \mathrm{v} / \mathrm{v} / \mathrm{v})$.

\section{6: HPLC method for acids and flavonoid}

Analysis of acids and flavonoid was performed on an Agilent 1100 series HPLC equipped with a quaternary pump, autosampler, photodiode array (PDA) and a degasser. The chromatographic method by Carbonara et al. [28] was used in the analysis with slight modifications. Briefly, the solvent system consisted of $\mathrm{A}(0.1 \%$ acetic acid, brought to $\mathrm{pH} 4$ with $\mathrm{NaOH})$ and $\mathrm{B}(0.1 \%$ acetic acid in acetonitrile $)$ using a gradient elusion of $0-60 \mathrm{~min}: 12-25 \% \mathrm{~B}, 60-80 \mathrm{~min}: 25-60 \% \mathrm{~B}, 80-85$ min: $60-100 \% \mathrm{~B}$. The system was equilibrated back to $12 \% \mathrm{~B}$ for 5 minutes before the next run. Analytes were separated and resolved at a flow rate of $1 \mathrm{~mL} \mathrm{~min}^{-1}$ on a Phenomenex Luna C18 column ( $250 \mathrm{~mm} \times 4.60 \mathrm{~mm}, 5 \mu \mathrm{m}$ particle size) attached to a $\mathrm{C} 18$ guard column. Detection and quantification was at $310 \mathrm{~nm}$ for caffeic acid, chlorogenic acids and isovitexin. Rosmarinic acid was analysed at $330 \mathrm{~nm}$ wavelength.

\section{7: Plasmodium assay}

Determination of $50 \%$ growth inhibitory concentration $\left(\mathrm{IC}_{50}\right)$ values of extracts, compounds and combinations against CQsensitive (CQS; HB3) and CQ-resistant (CQR; Dd2) strains of $P$. falciparum was performed at Georgetown University, Washington, DC, USA, using a previously reported protocol [36] with minor modifications. Typically, test samples were dissolved in DMSO to give a stock solution, followed by serial dilution using complete media (RPMI 1640 supplemented with $10 \%\left(\mathrm{v} / \mathrm{v}\right.$ ) type- $\mathrm{O}^{+}$human serum, $25 \mathrm{mM}$ HEPES ( $\mathrm{pH} 7.4$ ), 23 $\mathrm{mM} \mathrm{NaHCO}, 11 \mathrm{mM}$ glucose, $0.75 \mathrm{mM}$ hypoxanthine and 20 $\mu \mathrm{g} / \mathrm{L}$ gentamicin) to generate working stocks. $100 \mu \mathrm{L}$ of these stock solutions were transferred into pre-warmed $\left(37^{\circ} \mathrm{C}\right) 96$ well plates. $100 \mu \mathrm{L}$ of asynchronous parasite culture at $2 \%$ parasitemia, 4\% hematocrit was transferred into each drug $(A$. annua plant extract) pre-loaded well, for a final $1 \%$ parasitemia, $2 \%$ hematocrit. The final concentration of DMSO was $2.5 \%$. Plates were transferred to a gassed $\left(90 \% \mathrm{~N}_{2}, 5 \% \mathrm{O}_{2}, 5 \% \mathrm{CO}_{2}\right)$ airtight chamber and incubated at $37^{\circ} \mathrm{C}$ for 72 hours. Following this incubation, $50 \mu \mathrm{L}$ of $10 X$ SYBR Green I dye (diluted with complete media from a $10000 \mathrm{X}$ concentrate in DMSO) was added to each well and plates incubated for an additional 1 hour at $37{ }^{\circ} \mathrm{C}$ to allow DNA intercalation. Fluorescence was measured at $530 \mathrm{~nm}$ (490 excitation) on a Spectra GeminiEM plate reader (Molecular Devices, USA). $I_{50}$ values were obtained from sigmoidal curves fit of parasite growth vs. drug concentration using SigmaPlot 10.0, and are the average of three replicates. CQ was included as a positive control in the assay.

\section{8: Combination analysis}

Interactions between compounds were evaluated by isobologram analysis $[37,38]$. Briefly, a master stock solution is prepared for each compound such that its concentration following four or five twofold dilutions approximates the $I_{50}$. These stock solutions were mixed at ratios of 0:4, 1:3, 1:1, 3:1 and $4: 0 \quad(\mathrm{v} / \mathrm{v})$ to give working combination stocks. Subsequently, the combination stocks were twofold serially diluted to generate a full dose concentration range for each $\mathrm{v} / \mathrm{v}$ mixture, which were then analysed under standard growth inhibitory assay conditions (see above) to provide dose response curves and an $\mathrm{IC}_{50}$, for each component of each $\mathrm{v} / \mathrm{v}$ mixture.

\section{9: Data analysis for in vitro combination studies}

$\mathrm{IC}_{50}$ values for each compound alone and in the combination were used to calculate FICs (fractional inhibition concentrations) as described elsewhere $[39,40]$. The FICs were summated to obtain the fractional inhibition concentration index $\left(\mathrm{FIC}_{\text {index }}\right)$ for the combination as in the equation below:

$$
F I C_{\text {index }}=F I C_{A}+F I C_{B}
$$

where:

$$
\begin{aligned}
& F I C_{A}=\frac{I C_{50} \text { of Drug A in Combination }}{I C_{50} \text { of Drug A Alone }} \\
& F I C_{B}=\frac{I C_{50} \text { of Drug B in Combination }}{I C_{50} \text { of Drug B Alone }}
\end{aligned}
$$

The following categorisation was used to determine the type of interactions between compounds evaluated: synergy $\left(\mathrm{FIC}_{\text {index }}\right.$ $<0.9)$, additivity $\left(0.9<\mathrm{FIC}_{\text {index }}<1.5\right)$ and antagonism $\left(\mathrm{FIC}_{\text {index }}\right.$ $>1.5)[39,40]$.

\section{Result and Discussion}

\section{1: Composition of $A$. annua tea}

Table 1 shows the metabolites in the aqueous extract analysed by both MS/MS and HPLC methods and their quantities in milligrams per litre of extract. The compounds analysed were based on the in extenso analysis by Carbonara et al. [28], who showed them to be among the major metabolites (quantitatively) in $A$. annua tea infusions. Some of these metabolites (like 3-caffeoylquinic acid) also have important dietary profiles $[41,42]$. In addition, artemisininrelated compounds, which we have previously detected in such 
Table 1. Metabolites in the aqueous $A$. annua extract analysed by both MS/MS and HPLC methods quantified as milligrams per litre of tea.

\begin{tabular}{ll}
\hline Compound & Amount $\left(\mathrm{mg} \mathrm{L}^{-1}\right.$ of tea) \\
\hline Artemisinin & $47.5 \pm 0.8$ \\
Arteannuin B & $1.3 \pm 0.0$ \\
Dihydroartemisinic acid & $70.0 \pm 0.3$ \\
Caffeic acid & $0.8 \pm 0.00$ \\
3,5-Di-caffeoylquinic acid & $57.0 \pm 1.7$ \\
3-Caffeoylquinic acid & $72.0 \pm 1.6$ \\
4-Caffeoylquinic acid & $20.4 \pm 1.6$ \\
4,5-Di-caffeoylquinic acid & $31.6 \pm 4.0$ \\
5-Caffeoylquinic acid & $9.0 \pm 0.7$ \\
Isovitexin & $105.0 \pm 7.2$ \\
Rosmarinic acid & $1.1 \pm 0.0$ \\
\hline
\end{tabular}

*. Values are an average of triplicate determinations with \pm S.E.M.

doi: 10.1371/journal.pone.0080790.t001

extracts, were also analysed. The level of artemisinin reported $[2,19,21,28,43]$ for tea extract is varied and the values obtained in this study $\left(47.5 \mathrm{mg} \mathrm{L}^{-1}\right)$ are within the reported range. These could be due to variation in biomass and the tea preparation method that was employed, but might also be due to differences in the biomass-to-solvent ratio used. Carbonara et al. [28] used a solvent to biomass ratio of $26: 1(\mathrm{v} / \mathrm{w})$, while this study, as well as others $[19,21]$, employed the therapeutically recommended ratio $\left(200: 1\right.$, v/w or $\left.5 \mathrm{~g} \mathrm{~L}^{-1}\right)$ [44].

Dihydroartemisinic acid (4) (70 $\left.\mathrm{mg} \mathrm{L}^{-1}\right)$ and arteannuin B (5) (1.3 $\left.\mathrm{mg} \mathrm{L}^{-1}\right)$ are the only biosynthetic precursors of artemisinin detected in the tea extract using our method [35]. Therefore artemisinin is the only compound among the metabolites we analysed in the tea with significant $\left(\mathrm{IC}_{50}<1 \mu \mathrm{M}\right)$ anti-plasmodial activity (Table 2).

3-Caffeoylquinic acid (11) was found to be the most abundant $\left(72 \mathrm{mg} \mathrm{L}^{-1}\right)$ of the caffeic derivatives (11-17) in the analysed extract, followed by 3,5-di-caffeoylquinic acid (15) (57 $\left.\mathrm{mg} \mathrm{L}^{-1}\right)$. Caffeic acid (10) was the least abundant $\left(0.8 \mathrm{mg} \mathrm{L}^{-1}\right)$ of the evaluated acids. Isovitexin (8) was the only flavonoid analysed $\left(105 \mathrm{mg} \mathrm{L}^{-1}\right)$, being relatively abundant in the extract. Some classes of flavonoids have poor aqueous solubility and limited profiles of these compounds in aqueous extract have been reported $[27,28]$. Lower level of rosmarinic acid (9) $(1.1$ $\mathrm{mg} \mathrm{L}^{-1}$ ) was detected in our samples, compared to the levels found by De Magalhaes et al [43]. However, widely different concentrations of the acid were reported in the cultivars and samples they analysed. The acid was not detected in the analysis by Carbonara et al [28]. Van der Kooy and Verpoorte [21] have also shown that the method employed in preparing the hot water infusion does affect the amount of artemisinin and therefore other co-metabolites extracted. These differences in profiles and concentration levels of metabolites seem to suggest that composition of prepared tea infusions differ and is significantly influenced by method of preparation and the Artemisia cultivar used.
Table 2. $I C_{50}$ of extracts and components of $A$. annua in CQ-sensitive (HB3) and resistant (Dd2) strains.

\begin{tabular}{|c|c|c|}
\hline \multirow[b]{2}{*}{ Compound/extracts } & \multicolumn{2}{|l|}{$\mathrm{IC}_{50}(\mathrm{nM})^{\mathrm{a}}$} \\
\hline & HB3 strain & Dd2 strain \\
\hline Chloroquine (CQ) & $21.8 \pm 2.4$ & $202.9 \pm 10.7$ \\
\hline Artemisinin & $22.6 \pm 0.7$ & $21.2 \pm 2.3$ \\
\hline Artesunate & $8.8 \pm 0.3$ & $5.6 \pm 0.6$ \\
\hline Artemisitene & $88.4 \pm 9.9$ & $74.1 \pm 7.8$ \\
\hline 9-epi-artemisinin & $59.2 \pm 1.7$ & $62.2 \pm 1.0$ \\
\hline \multirow[t]{2}{*}{ Artemisia aqueous extract $(T e a)^{b}$} & $7.6 \pm 3.4$ & $2.9 \pm 0.4$ \\
\hline & \multicolumn{2}{|l|}{$\mathrm{IC}_{50}(\mu \mathrm{M})^{\mathrm{a}}$} \\
\hline Artemisinic acid & $77.8 \pm 1.5$ & $61.6 \pm 7.5$ \\
\hline Arteannuin B & $3.2 \pm 0.1$ & $4.8 \pm 0.4$ \\
\hline Dihydroartemisinic acid & $21.1 \pm 0.7$ & $17.7 \pm 4.2$ \\
\hline Caffeic acid & $60.4 \pm 4.3$ & $47.5 \pm 8.8$ \\
\hline 3-Caffeoylquinic acid & $69.4 \pm 6.4$ & $61.4 \pm 4.3$ \\
\hline 4-Caffeoylquinic acid & $61.4 \pm 4.3$ & $53.6 \pm 5.0$ \\
\hline 5-Caffeoylquinic acid & $84.8 \pm 6.4$ & $85.3 \pm 4.2$ \\
\hline 3,4-Caffeoylquinic acid & $36.2 \pm 1.0$ & $49.0 \pm 6.8$ \\
\hline 4,5-Caffeoylquinic acid & $29.3 \pm 2.4$ & $43.2 \pm 4.2$ \\
\hline 3,4,5-Caffeoylquinic acid & $181.4 \pm 2.1$ & $88.2 \pm 6.2$ \\
\hline Rosmarinic acid & $65.1 \pm 5.0$ & $65.0 \pm 7.0$ \\
\hline Isovitexin & $72.5 \pm 6.8$ & $48.1 \pm 4.5$ \\
\hline Casticin & $17.9 \pm 4.7$ & $12.2 \pm 1.8$ \\
\hline
\end{tabular}

a $\mathrm{IC}_{50}$ values are an average of at least three independent measurements each performed in triplicate, and are shown \pm S.E.M of the three independent experiments. ${ }^{b} \mathrm{IC}_{50}$ of extract determined based on the artemisinin content (i.e. ART IC 50 of extract) see Table 2 .

doi: 10.1371/journal.pone.0080790.t002

\section{2: Anti-plasmodium extracts and bioactive compounds in $A$. annua}

Table 2 shows $I_{50}$ anti-plasmodial values for pure compounds and extracts of $A$. annua plant. Between three- and seven-fold potentiation of artemisinin activity was observed for $A$.annua aqueous (tea) extract in CQ-sensitive (HB3) and CQresistant (Dd2) strains respectively. Only artemisitene (3) $\left(\mathrm{IC}_{50}\right.$, 88.4 $\pm 9.9 / 74.1 \pm 7.8 \mathrm{nM}, \mathrm{HB} 3 / \mathrm{Dd} 2$ ) and 9-epi-artemisinin (2) $\left(\mathrm{IC}_{50}, 59.2 \pm 1.7 / 62.2 \pm 1.0 \mathrm{nM}, \mathrm{HB} 3 / \mathrm{Dd} 2\right)$ showed significant antiplasmodial activities $\left(\mathrm{IC}_{50}<1 \mu \mathrm{M}\right)$ among the artemisinin biosynthetic precursors evaluated. 9-Epi-artemisinin and artemisitene respectively showed about one third and one fourth of the activity of artemisinin. Acton et al. [45] observed a similarly reduced activity for 9-epi-artemisinin and artemisitene, compared to artemisinin in D6 and W2 strains of $P$. falciparum. Artemisinin has a chiral molecular structure and the bioactivity of the molecule is influenced by its absolute configuration.

To investigate if solubility of these artemisinin analogues could be partially responsible for the reduced activity, we determined the aqueous solubilities of artemisinin, artemisitene and 9 -epi-artemisnin. Table 3 shows the solubility of these compounds at experimental conditions.

Under these conditions, 9-epi-artemisinin has a higher solubility, about twice that of artemisinin or artemisitene. The lower bioactivity could not be explained based on the solubility 
Table 3. Solubility of artemisinin, artemisitene and 9-epiartemisinin in water at $22{ }^{\circ} \mathrm{C}$ and atmospheric pressure.

\begin{tabular}{ll}
\hline Compound & Solubility $\left[\mathrm{mg} \mathrm{L}^{-1}\right]^{*}$ at $\mathbf{2 2}{ }^{\circ} \mathbf{C}$ \\
\hline Artemisinin & $74.27 \pm 2.10$ \\
Artemisitene & $74.21 \pm 2.99$ \\
9-Epi-artemisinin & $133.08 \pm 5.44$ \\
\hline
\end{tabular}

*. Values are an average of triplicate determinations with \pm S.E.M.

doi: 10.1371 /journal.pone .0080790. to03

data alone, although the experimental data was obtained at 22 ${ }^{\circ} \mathrm{C}$ (Table 3). We do not expect the pattern observed to change significantly at physiological conditions.

Woerdenbag et al. [46] observed that the anti-cancer activity of 11-hydroxy-11-epi-artemisinin (C11 in older and C9 in newer references for the structure) was about threefold less than the conformer, which is the same threefold difference we observed in the anti-plasmodial activity for epimerisation at C9 (Table 2). If the threefold activity difference is consistent regardless of the differences in molecular targets and effect, this may suggest a common upstream differentiation point of molecule activation. The lower activity of 9-epi-artemisinin may therefore be due in part to a structural conformation that is relatively more difficult to activate compared to artemisinin.

\section{3: Antagonism of artemisinin with biosynthetic precursors}

Figure 2 shows the interaction of artemisitene and 9-epiartemisinin with artemisinin and artesunate (6). These biosynthetic precursors of artemisinin have significant $\left(\mathrm{IC}_{50}<1\right.$ $\mu \mathrm{M})$ anti-plasmodial activities (Table 2). The interaction of artemisinin with 9-epi-artemisinin and artemisitene was antagonistic, but the interaction of these compounds with artesunate was additive in both chloroquine sensitive (HB3) and resistant (Dd2) strains.

The reason for the observed antagonistic interaction with artemisinin at the combinations investigated is unclear. Structurally, artemisinin, 9-epi-artemisinin and artemisitene are differentiated at $\mathrm{C9}$. The difference from artemisinin is epimerisation of the methyl group for 9-epi-artemisinin and a methylene group attached instead for artemisitene (Figure 1). Given the minor structural differences, it is likely that these compounds have identical molecular targets and therefore possibly compete for these when combined. Conversely, due to the relatively large difference in structure and mass of artesunate and 9-epi-artemisinin or artemisitene, these compounds, when combined, may act on the same targets as well as on different molecular targets with the possibility of positive polyvalent interaction. Similarly, Wagner [47-49] has reported an in vitro synergistic inhibitory effect upon combining ginkgolides A and B from Ginkgo biloba extract for PAFinduced thrombocyte-aggregation. The difference between ginkgolide $A$ and $B$ is an oxygen atom (16 Da).

\section{4: Analysis of other combinations}

Table 4 shows the interaction of co-metabolites in $A$. annua extracts with artemisinin. In the $C Q$-sensitive (HB3) strain, 3caffeoylquinic acid (3CA) showed additive interaction at 1:3 $(\mathrm{v} / \mathrm{v})$, which became synergistic at higher ratio of the acid to artemisinin $(1: 10,1: 100 \mathrm{v} / \mathrm{v})$. For casticin, the interaction at 1:3 (artemisinin to casticin, $v / v$ ) is antagonistic. Synergistic interaction is however reported [24,25] for combination ratios at the range of 1:10-1000 (artemisinin to casticin, v/v).

Therefore, using the FIC index of casticin (1.9) as a benchmark for potential positive interactions, compounds like isovitexin, caffeic acid and dihydroartemisinic acid that show antagonistic interactions at 1:3 may also, like casticin, interact synergistically at a higher ratio. Rosmarinic acid was synergistic at a 1:3 combination with artemisinin (v/v) and some chlorogenic acids were additive at this combination also. These compounds showing positive interactions with artemisinin may collectively be responsible for the potentiation of artemisinin in the tea extract. However, arteannuin B and artemisinic acid are poorly extracted in the aqueous extract.

Casticin and 3-caffeoylquinic acid (3CA) are polyphenolic compounds that are natural anti-oxidants. Anti-oxidants at cellular redox sites are considered a "double edged sword" able to act either as anti-oxidant or pro-oxidant depending on conditions, such as dosage levels and presence of metal ions [50,51]. This "double edged sword" characteristic of antioxidant polyphenols could help explain our observation. At a lower combination with artemisinin, casticin and 3CA were antioxidative towards the ROS and carbon-centred radicals formed from artemisinin activation and, as a result, countered artemisinin activity in vitro. Conversely, at a higher concentration ratio to artemisinin, casticin and 3CA were prooxidative, enhancing the oxidative stress resulting from artemisinin's activation, leading to improvement in artemisinin's potency. A schematic isobologram to describe the interaction between an active pharmaceutical ingredient (API) like artemisinin (A) and synergists like casticin and 3CA (B, non$A P I)$ is shown in Figure 3.

\section{5: Possible role of anti-oxidant defence network in resistance}

Rosmarinic acid at the combination ratio evaluated had a potentiating effect $\left(\mathrm{FIC}_{\text {index }} 0.89\right)$ on artemisinin in the $\mathrm{CQ}$ sensitive (HB3) strain (Table 4) but this effect was not reproduced in the resistant (Dd2) strain; rather a strong antagonistic effect $\left(\mathrm{FIC}_{\text {index }} 4.95\right)$ was observed. The effect of rosmarinic acid on artemisinin's ability to mitigate the resistance mechanism of the parasite could be partly explained by the finding of Cul et al. [52] and others [53] who observed that in vitro resistance in $P$. falciparum is associated with increased pfmdr-1 copy number and anti-oxidant activity. Some experiments with rosmarinic acid have reported strong antioxidant activity for the compound that is over three times that of trolox [54-56]. In the presence of rosmarinic acid, anti-oxidant activity may further be elevated thereby promoting increased resistance. A similar trend of activity in sensitive and resistant parasite strains in combination with artemisinin was observed for caffeic acid, 4-caffeoyl-quinic acid (12) and isovitexin with 

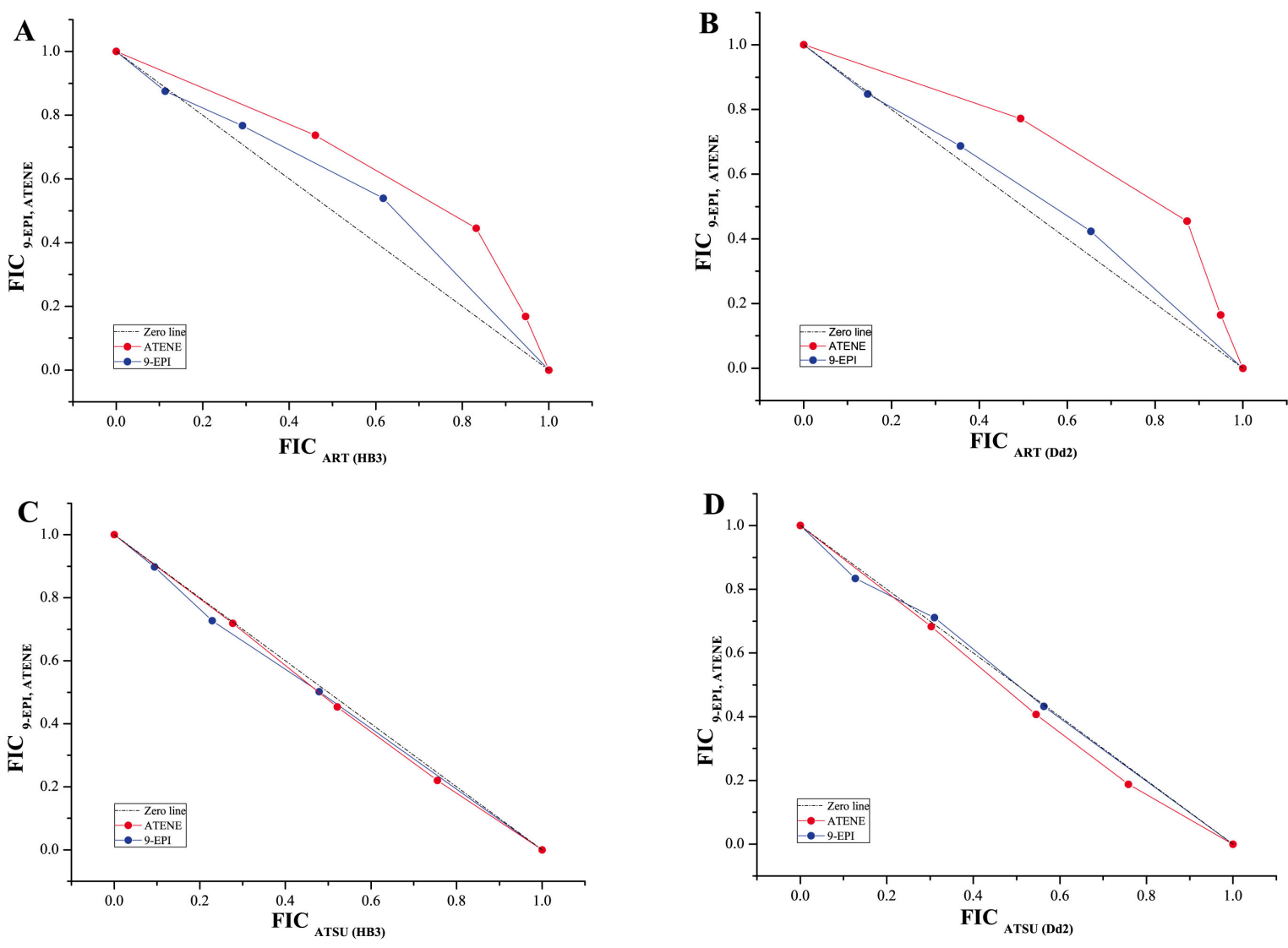

Figure 2. Isobologram showing the plot of fractional inhibitory concentration (FIC) of 9-epi-artemisinin (EPI) and artemisitene (ATENE) against FIC of artemisinin (ART) and artesunate (ATSU). Panel A - interaction of EPI and ATENE with ART in chloroquine-sensitive (CQS) HB3 strain. Panel B - same as in A but in CQ-resistant (CQR) Dd2 strain. Panel C - interaction of EPI and ATENE with ATSU in HB3. Panel D - same as C but in Dd2 parasite.

doi: 10.1371/journal.pone.0080790.g002

reported anti-oxidant properties [57-59]. This supports the possible role of the anti-oxidant defence network in parasite resistance to artemisinin [60]

\section{6: Arteannuin B selectively potentiates the activity of artemisinin against parasite defence system}

Arteannuin B at $3: 1(\mathrm{v} / \mathrm{v})$ combination with artemisinin showed additive or no interaction $\left(\mathrm{FIC}_{\text {index }} 1.25\right)$ in the $\mathrm{CQ}$ sensitive strain and a synergistic interaction $\left(\mathrm{FIC}_{\text {index }} 0.34\right)$ in the resistant parasite strain (Table 4). This is about a three-fold improvement in artemisinin's potency against CQ-resistant $P$. falciparum. This is not reproduced in the CQ-sensitive strain. The potentiation of artemisinin by arteannuin B seems to be selectively directed at the parasites' chloroquine resistance mechanism. This combination could therefore help to better understand the mechanism(s) involved in parasite defence network. Reproducing this three-fold improvement in potency with other artemisinin analogues could also help in the development of therapeutics effective against emerging drugresistant strains.

Arteannuin B is an unusual a-methylene-y-lactone, transfused via a tertiary hydroxyl group [61]. This structure could account for its easy fragmentation/ionisation observed in mass spectrometry and reported facile rearrangement in acidic conditions [35,62].

\section{4: Conclusions}

In this study we examine interactions between artemisinin and co-metabolites found in $A$. annua plant extracts for chloroquine sensitive (CQS; HB3) and resistant (CQR; Dd2) $P$. falciparum malarial parasites. The aqueous extract (tea) showed about three to seven-fold potentiation in the parasite strains. When pure compounds were combined, 9-epi- 
Table 4. Anti-plasmodial interactions of co-metabolites with artemisinin in CQ-sensitive (HB3) and CQ-resistant (Dd2) strains.

\begin{tabular}{lllll}
\hline & HB3 & & Dd2 & \\
\cline { 2 - 5 } Combination & FIC $_{\text {index }}$ & Interaction & FIC $_{\text {index }}$ & Interaction \\
\hline 1:3 ART:CA & 1.570 & Antagonistic & 4.046 & Antagonistic \\
1:3 ART:3CA & 1.172 & Additive & 2.088 & Antagonistic \\
1:10 ART:3CA & 0.685 & Synergistic & 1.087 & Additive \\
1:100 ART:3CA & 0.781 & Synergistic & 1.177 & Additive \\
1:3 ART:4CA & 1.088 & Additive & 4.266 & Antagonistic \\
1:3 ART:5CA & 0.928 & Additive & 2.460 & Antagonistic \\
1:3 ART:34CA & 2.253 & Antagonistic & 4.862 & Antagonistic \\
1:3 ART:35CA & 2.312 & Antagonistic & 4.749 & Antagonistic \\
1:3 ART:45CA & 2.315 & Antagonistic & 4.844 & Antagonistic \\
1:3 ART:TCA & 1.220 & Additive & 3.041 & Antagonistic \\
1:3 ART:ISO & 1.534 & Antagonistic & 4.829 & Antagonistic \\
1:3 ART:CAS & 1.921 & Antagonistic & 3.034 & Antagonistic \\
1:3 ART:ATCID & 1.467 & Additive & 4.152 & Antagonistic \\
1:3 ART:ARTB & 1.250 & Additive & 0.342 & Synergistic \\
1:3 ART:RA & 0.890 & Synergistic & 4.952 & Antagonistic \\
1:3 ART:DHAA & 1.801 & Antagonistic & 2.861 & Antagonistic \\
1:3 ART:ATENE & 3.480 & Antagonistic & 7.002 & Antagonistic \\
ART & 1 & - & 1 & - \\
\hline Aft & & & & \\
\hline
\end{tabular}

Art $=$ artemisinin, $\mathrm{CA}=$ caffeic acid, $3 \mathrm{CA}=3$-caffeoylquinic acid, $4 \mathrm{CA}=4$ caffeoylquinic acid, 5CA $=5$-caffeoylquinic acid, 3,4 CA $=3$,4-di-caffeoylquinic acid, 3,5CA = 3,5-di-caffeoylquinic acid, 4,5CA = 4,5-di-caffeoylquinic acid, TCA = 3,4,5-tri-caffeoylquinic acid, ISO = siovitexin, CAS = casticin, ATCID = artemisinic acid, $A R T B=$ arteannuin $B, R A=$ rosmarinic acid, DHAA = dihydroartemisinic acid, ATENE $=$ artemisitene

doi: 10.1371/journal.pone.0080790.t004

\section{Substance A}

(API)

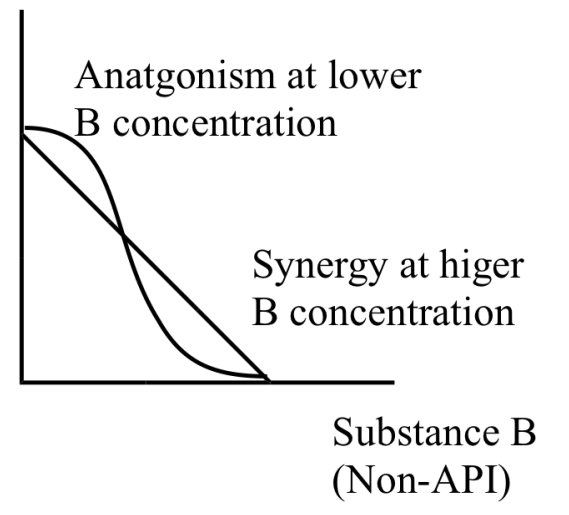

Figure 3. A schematic isobologram of the interaction of artemisinin (API) with anti-oxidant synergist (Non-API).

doi: 10.1371/journal.pone.0080790.g003

artemisinin and artemisitene interacted antagonistically with artemisinin at the combinations evaluated. 9-epi-artemisinin and artemisitene were the only artemisinin-related metabolites with significant anti-plasmodial activity $\left(\mathrm{IC}_{50}<1 \mu \mathrm{M}\right)$ among those evaluated. In CQS parasites, caffeic acids and their chlorogenic acid derivatives showed additive interactions with artemisinin at the combination ratio evaluated. 3-Caffeoylquinic acid's interaction with artemisinin turned synergistic with the increased ratio of the former in the combination. Rosmarinic acid showed synergistic interaction with artemisinin in the drug sensitive strain but the interaction with artemisinin in the drug resistant strain was strongly antagonistic at the same level of combination. This antagonistic interaction in CQR parasites was also observed for caffeic acid and some of its derivatives known to have anti-oxidant properties. The observation supports literature evidence $[52,53]$ for a potential role of antioxidants in parasite drug resistance. Therefore the effect of dietary anti-oxidants on artemisinin combination therapies used in the management of drug resistant $P$. falciparium malaria may need to be further investigated.

Arteannuin B was found to selectively potentiate the activity of artemisinin in Dd2 parasites, suggesting some interaction with the CQR mechanism, since the potentiation of artemisinin by arteannuin B was not reproduced in CQS parasites. As a result of this specificity, arteannuin $B$ could potentially be used as a probe to better understand parasite drug resistance mechanisms and the combination might prove useful for treating CQR strains of malaria.

\section{Acknowledgements}

The authors would like to acknowledge earlier assistance with in vitro assay done in Prof. Steve Ward's laboratory (Liverpool School of Tropical Medicine) by Mrs. Jill Davies, which provided a foundation for the current work. The authors also thank Ms. Katy Sherlach (Georgetown University, USA) for technical help and helpful discussions and are grateful to BIONEXX (Madagascar) and Charles Giblane for supply of $A$. annua biomass.

\section{Author Contributions}

Conceived and designed the experiments: JS GB AL PR. Performed the experiments: JS AG LJ. Analyzed the data: JS AG. Contributed reagents/materials/analysis tools: NS. Wrote the manuscript: JS GB AL. 


\section{References}

1. Hsu $E$ (2006) The history of qing hao in the Chinese materia medica. Trans R Soc Trop Med Hyg 100: 505-508. doi:10.1016/j.trstmh. 2005.09.020. PubMed: 16566952

2. Wright CW, Linley PA, Brun R, Wittlin S, Hsu E (2010) Ancient Chinese methods are remarkably effective for the preparation of artemisinin-rich extracts of Qing Hao with potent antimalarial activity. Molecules 15: 804-812. doi:10.3390/molecules15020804. PubMed: 20335947.

3. O'Neill PM, Barton VE, Ward SA (2010) The molecular mechanism of action of artemisinin-the debate continues. Molecules 15: 1705-1721. doi:10.3390/molecules15031705. PubMed: 20336009.

4. Ding XC, Beck H-P, Raso G (2011) Plasmodium sensitivity to artemisinins: magic bullets hit elusive targets. Trends Parasitol 27: 73-81. doi:10.1016/j.pt.2010.11.006. PubMed: 21169061.

5. Pandey AV, Tekwani BL, Singh RL, Chauhan VS (1999) Artemisinin, an endoperoxide antimalarial, disrupts the hemoglobin catabolism and heme detoxification systems in malarial parasite. J Biol Chem 274: 19383-19388. doi:10.1074/jbc.274.27.19383. PubMed: 10383451.

6. Jefford CW (2001) Why artemisinin and certain synthetic peroxides are potent antimalarials. Implications for the mode of action. Curr Med Chem 8: 1803-1826. doi:10.2174/0929867013371608. PubMed: 11772352.

7. Eckstein-Ludwig U, Webb RJ, Van Goethem ID, East JM, Lee AG et al. (2003) Artemisinins target the SERCA of Plasmodium falciparum. Nature 424: 957-961. doi:10.1038/nature01813. PubMed: 12931192.

8. Wang J, Huang L, Li J, Fan Q, Long Y et al. (2010) Artemisinin Directly Targets Malarial Mitochondria through Its Specific Mitochondrial Activation. PLOS ONE 5: e9582. doi:10.1371/journal.pone.0009582. PubMed: 20221395

9. Li W, Mo W, Shen D, Sun L, Wang J et al. (2005) Yeast Model Uncovers Dual Roles of Mitochondria in the Action of Artemisinin. PLOS Genet 1: e36. doi:10.1371/journal.pgen.0010036. PubMed: 16170412.

10. Haynes RK, Monti D, Taramelli D, Basilico N, Parapini S et al. (2003) Artemisinin antimalarials do not inhibit hemozoin formation. Antimicrob Agents Chemother 47: 1175-1175. doi:10.1128/AAC.47.3.1175.2003. PubMed: 12604568.

11. Golenser J, Waknine JH, Krugliak M, Hunt NH, Grau GE (2006) Current perspectives on the mechanism of action of artemisinins. Int $\mathrm{J}$ Parasitol 36: 1427-1441. doi:10.1016/j.ijpara.2006.07.011. PubMed: 17005183.

12. Eastman RT, Fidock DA (2009) Artemisinin-based combination therapies: a vital tool in efforts to eliminate malaria. Nat Rev Microbiol 7: 864-874. PubMed: 19881520.

13. Klonis N, Crespo-Ortiz MP, Bottova I, Abu-Bakar N, Kenny S et al. (2011) Artemisinin activity against Plasmodium falciparum requires hemoglobin uptake and digestion. Proc Natl Acad Sci USA 108: 11405-11410. doi:10.1073/pnas.1104063108. PubMed: 21709259.

14. Haynes RK (2006) From artemisinin to new artemisinin antimalarials: biosynthesis, extraction, old and new derivatives, stereochemistry and medicinal chemistry requirements. Curr Top Med Chem 6: 509-537. doi:10.2174/156802606776743129. PubMed: 16719805.

15. Weina PJ (2008) Artemisinins from Folklore to Modern MedicineTransforming an Herbal Extract to Life-Saving Drugs. Parassitologia 50: 25-29. PubMed: 18693553.

16. Jansen $\mathrm{FH}$ (2006) The herbal tea approach for artemisinin as a therapy for malaria? Trans R Soc Trop Med Hyg 100: 285-286. doi:10.1016/ j.trstmh.2005.08.004. PubMed: 16274712

17. WHO Report (2012) WHO position statement on effectiveness of nonpharmaceutical forms of Artemisia annua L. against malaria. Available: http://www.who.int/malaria/ position_statement_herbal_remedy_artemisia_annua_I.pdf.

18. Hsu E (2006) Reflections on the discovery of the antimalarial qinghao. $\mathrm{Br} J$ Clin Pharmacol 61: 666-670. doi:10.1111/j. 1365-2125.2006.02673.x. PubMed: 16722826.

19. Rath K, Taxis K, Walz G, Gleiter CH, Li SM et al. (2004) Pharmacokinetic study of artemisinin after oral intake of a traditional preparation of Artemisia annua L.(annual wormwood). The American journal of tropical medicine and hygiene 70: 128-132

20. De Ridder S, Van der Kooy F, Verpoorte R (2008) Artemisia annua as a self-reliant treatment for malaria in developing countries. J Ethnopharmacol 120: 302-314. doi:10.1016/j.jep.2008.09.017. PubMed: 18977424.

21. Van der Kooy F, Verpoorte R (2011) The Content of Artemisinin in the Artemisia annua Tea Infusion. Planta Medica-Natural Products and Medicinal. J Plant Res 77: 1754. doi:10.1055/s-0030-1271065.

22. Mouton J, Jansen O, Frédérich M, van der Kooy F (2013) Is Artemisinin the Only Antiplasmodial Compound in the Artemisia annua Tea
Infusion? An in Vitro Study. Planta Med 79: 468-470. doi:10.1055/ s-0032-1328324. PubMed: 23512495.

23. Willcox M, Bodeker G, Bourdy G, Dhingra V, Falquet J et al. (2004) Artemisia annua as a traditional herbal antimalarial. Tradit Med Plants Malar: 43-59.

24. Liu K, Yang S-L, Roberts M, Elford B, Phillipson J (1992) Antimalarial activity of Artemisia annua flavonoids from whole plants and cell cultures. Plant Cell Rep 11: 637-640.

25. Elford BC, Roberts MF, Phillipson JD, Wilson RJM (1987) Potentiation of the antimalarial activity of qinghaosu by methoxylated flavones. Trans R Soc Trop Med Hyg 81: 434-436. doi: 10.1016/0035-9203(87)90161-1. PubMed: 3318019.

26. Bilia AR, Lazari D, Messori L, Taglioli V, Temperini C et al. (2002) Simple and rapid physico-chemical methods to examine action of antimalarial drugs with hemin: its application to Artemisia annua constituents. Life Sci 70: 769-778. doi:10.1016/ S0024-3205(01)01447-3. PubMed: 11833740.

27. Weathers PJ, Towler MJ (2012) The flavonoids casticin and artemetin are poorly extracted and are unstable in an Artemisia annua tea infusion. Planta Med 78: 1024-1026. doi:10.1055/s-0032-1314949. PubMed: 22673829

28. Carbonara T, Pascale R, Argentieri MP, Papadia P, Fanizzi FP et al. (2012) Phytochemical analysis of a herbal tea from Artemisia annua $L$. J Pharm Biomed Anal 62: 79-86. doi:10.1016/j.jpba.2012.01.015. PubMed: 22305080.

29. Zhang B, Yang R, Liu CZ (2008) Microwave-assisted extraction of chlorogenic acid from flower buds of Lonicera japonica Thunb. Sep Purif Technol 62: 480-483. doi:10.1016/j.seppur.2008.02.013.

30. Feng R, Lu Y, Bowman LL, Qian Y, Castranova V et al. (2005) Inhibition of activator protein-1, NF-kappaB, and MAPKs and induction of phase 2 detoxifying enzyme activity by chlorogenic acid. J Biol Chem 280: 27888-27895. doi:10.1074/jbc.M503347200. PubMed: 15944151.

31. Miketova P, Schram KH, Whitney J, Kearns EH, Timmermann BN (1999) Mass spectrometry of 3,5- and 4,5-dicaffeoylquinic acids and selected derivatives. J Mass Spectrom 34: 1240-1252. doi:10.1002/ (SICl)1096-9888(199912)34:12. PubMed: 10587617

32. Belkaid A, Currie J-C, Desgagnés J, Annabi B (2006) The chemopreventive properties of chlorogenic acid reveal a potential new role for the microsomal glucose-6-phosphate translocase in brain tumor progression. Cancer Cell Int 6: 7. doi:10.1186/1475-2867-6-7. PubMed: 16566826.

33. De Donno A, Grassi T, Idolo A, Guido M, Papadia P et al. (2012) Firsttime comparison of the in vitro antimalarial activity of Artemisia annua herbal tea and artemisinin. Trans R Soc Trop Med Hyg 106: 696-700. doi:10.1016/j.trstmh.2012.07.008. PubMed: 22986092

34. Wang L-H, Song Y-T, Chen Y, Cheng Y-Y (2007) Solubility of Artemisinin in Ethanol + Water from (278.2 to 343.2) K. J Chem Eng Data 52: 757-758. doi:10.1021/je0603426

35. Suberu J, Song L, Slade S, Sullivan N, Barker G et al. (2013) A rapid method for the determination of artemisinin and its biosynthetic precursors in Artemisia annua L. crude extracts. J Pharm Biomed Anal 84: 269-277. doi:10.1016/j.jpba.2013.06.025. PubMed: 23867088.

36. Bennett TN, Paguio M, Gligorijevic B, Seudieu C, Kosar AD et al. (2004) Novel, rapid, and inexpensive cell-based quantification of antimalarial drug efficacy. Antimicrob Agents Chemother 48: 1807-1810. doi:10.1128/AAC.48.5.1807-1810.2004. PubMed: 15105139.

37. Bray PG, Deed S, Fox E, Kalkanidis M, Mungthin M et al. (2005) Primaquine synergises the activity of chloroquine against chloroquineresistant $P$. falciparum. Biochem Pharmacol 70: 1158-1166. doi: 10.1016/j.bcp.2005.07.021. PubMed: 16139253.

38. Berenbaum MC (1978) A method for testing for synergy with any number of agents. J Infect Dis 137: 122-130. doi:10.1093/infdis/ 137.2.122. PubMed: 627734.

39. Vivas L, Rattray L, Stewart LB, Robinson BL, Fugmann B et al. (2007) Antimalarial efficacy and drug interactions of the novel semi-synthetic endoperoxide artemisone in vitro and in vivo. J Antimicrob Chemother 59: 658-665. doi:10.1093/jac/dkl563. PubMed: 17337512.

40. Fivelman QL, Adagu IS, Warhurst DC (2004) Modified fixed-ratio isobologram method for studying in vitro interactions between atovaquone and proguanil or dihydroartemisinin against drug-resistant strains of Plasmodium falciparum. Antimicrob Agents Chemother 48: 4097-4102. doi:10.1128/AAC.48.11.4097-4102.2004. PubMed: 15504827.

41. Friedman M (1997) Chemistry, biochemistry, and dietary role of potato polyphenols. A review. J Agric Food Chem 45: 1523-1540. doi:10.1021/ jf960900s. 
42. Noratto G, Porter W, Byrne D, Cisneros-Zevallos L (2009) Identifying peach and plum polyphenols with chemopreventive potential against estrogen-independent breast cancer cells. J Agric Food Chem 57: 5219-5226. doi:10.1021/jf900259m. PubMed: 19530711.

43. De Magalhaes PM, Dupont I, Hendrickx A, Joly A, Raas T et al. (2012) Anti-inflammatory effect and modulation of cytochrome P450 activities by Artemisia annua tea infusions in human intestinal Caco-2 cells. Food Chem 134: 864-871. doi:10.1016/j.foodchem.2012.02.195. PubMed: 23107701.

44. Willcox M (2009) Artemisia species: from traditional medicines to modern antimalarials-and back again. J Altern Complement Med 15: 101-109. doi:10.1089/acm.2008.0327. PubMed: 19236169.

45. Acton N, Klayman DL (1987) Conversion of artemisinin (qinghaosu) to iso-artemisitene and to 9-epi-artemisinin1. Planta Med 53: 266-268. doi:10.1055/s-2006-962700. PubMed: 17269016

46. Woerdenbag HJ, Moskal TA, Pras N, Malingré TM, El-Feraly FS et al. (1993) Cytotoxicity of Artemisinin-Related Endoperoxides to Ehrlich Ascites Tumor Cells. J Nat Prod 56: 849-856. doi:10.1021/ np50096a007. PubMed: 8350087.

47. Wagner H, Ulrich-Merzenich G (2009) Synergy research: Approaching a new generation of phytopharmaceuticals. Phytomedicine 16: 97-110. doi:10.1016/j.phymed.2008.12.018. PubMed: 19211237

48. Wagner $H$ (2011) Synergy research: Approaching a new generation of phytopharmaceuticals. Fitoterapia 82: 34-37. doi:10.1016/j.fitote. 2010.11.016. PubMed: 21075177.

49. Wagner $\mathrm{H}(2005)$ Natural products chemistry and phytomedicine in the 21st century: new developments and challenges. Pure Appl Chem 77: 1-6. doi:10.1351/pac200577010001.

50. Yordi EG, Pérez EM, Matos MJ, Villares EU (2012) Antioxidant and Pro-Oxidant Effects of Polyphenolic Compounds and Structure-Activity Relationship Evidence. Nutrition, Well-Being and Health. Intech.

51. Nemeikaitè-Čènienè A, Imbrasaite A, Sergediene E, Čènas N (2005) Quantitative structure-activity relationships in prooxidant cytotoxicity of polyphenols: role of potential of phenoxyl radical/phenol redox couple. Arch Biochem Biophys 441: 182-190. doi:10.1016/j.abb.2005.07.002. PubMed: 16111645

52. Cui L, Wang ZL, Miao J, Miao M, Chandra R et al. (2012) Mechanisms of in vitro resistance to dihydroartemisinin in Plasmodium falciparum.
Mol Microbiol 86: 111-128. doi:10.1111/j.1365-2958.2012.08180.x. PubMed: 22812578.

53. Sidhu ABS, Uhlemann A-C, Valderramos SG, Valderramos J-C Krishna $S$ et al. (2006) Decreasing pfmdr1 copy number in Plasmodium falciparum malaria heightens susceptibility to mefloquine, lumefantrine, halofantrine, quinine, and artemisinin. J Infect Dis 194: 528-535. doi: 10.1086/507115. PubMed: 16845638.

54. Erkan N, Ayranci G, Ayranci E (2008) Antioxidant activities of rosemary (Rosmarinus Officinalis L.) extract, blackseed (Nigella sativa L.) essential oil, carnosic acid, rosmarinic acid and sesamol. Food Chemistry 110: 76-82

55. Petersen M, Simmonds MSJ (2003) Rosmarinic acid. Phytochemistry 62: 121-125. doi:10.1016/S0031-9422(02)00513-7. PubMed: 12482446 .

56. Tepe B, Eminagaoglu O, Akpulat HA, Aydin E (2007) Antioxidant potentials and rosmarinic acid levels of the methanolic extracts of Salvia verticillata (L.) subsp. verticillata and S. verticillata (L.) subsp. amasiaca (Freyn \&amp; Bornm.) Bornm. Food Chemistry 100: 985-989..

57. Gülçin i (2006) Antioxidant activity of caffeic acid (3,4dihydroxycinnamic acid). Toxicology 217: 213-220. doi:10.1016/j.tox. 2005.09.011. PubMed: 16243424

58. Xu J-G, Hu Q-P, Liu Y (2012) Antioxidant and DNA-Protective Activities of Chlorogenic Acid Isomers. J Agric Food Chem 60: 11625-11630. doi: 10.1021/jf303771s. PubMed: 23134416.

59. Cao D, Li H, Yi J, Zhang J, Che H et al. (2011) Antioxidant Properties of the Mung Bean Flavonoids on Alleviating Heat Stress. PLOS ONE 6: e21071. doi:10.1371/journal.pone.0021071. PubMed: 21695166.

60. Bozdech Z, Ginsburg H (2004) Antioxidant defense in Plasmodium falciparum-data mining of the transcriptome. Malar J 3: 23. doi: 10.1186/1475-2875-3-23. PubMed: 15245577.

61. Agrawal PK, Vishwakarma RA, Jain DC, Roy R (1991) High field NMR spectroscopic studies of arteannuin $B$ and a reappraisal of the structure of arteannuin C. Phytochemistry 30: 3469-3471. doi: 10.1016/0031-9422(91)83234-C.

62. Lansbury PT, Mojica CA (1986) Total synthesis of $( \pm)$-arteannuin B. Tetrahedron Lett 27: 3967-3970. doi:10.1016/S0040-4039(00)84886-8. 